\title{
Analysis on How to Deal with the Problem of Correlation among Different Securities
}

\author{
Wenyou Gao ${ }^{1}$ \\ ${ }^{1}$ School of Economics and Management, Chang Chun University of Science and Technology, Chang Chun, Jilin, \\ 130022, China \\ Correspondence: Wenyou Gao, School of Economics and Management, Chang Chun University of Science and \\ Technology, Chang Chun, Jilin, 130022, China. E-mail: mhymark@gmail.com
}

Received: September 2, 2014

Accepted: October 10, 2014

Online Published: October 13, 2014

doi:10.5430/jbar.v3n2p82

URL: http://dx.doi.org/10.5430/jbar.v3n2p82

\begin{abstract}
By analyzing the correlation among many kinds of securities, the paper hopes to solve the financial problems on how to establish securities combination in relevant financial markets .Meanwhile, through comparing with traditional portfolio theories, the writer wants to help all kinds of investors realize the arbitraging purpose by using new method with researching relative model of Portfolios more deeply and more theoretically.
\end{abstract}

Keywords: Correlation coefficient, Standard deviation, Variance, Co-variance

\section{Introduction}

\subsection{General Conceptions on Correlation}

How to realize the question of "Correlation" is crucial in any of Portfolios - either regarding to configuration of various financial assets or making copies for all kinds of securities, we should find the positive and negative relations among them thereof to measure divergent financial instruments. In two types of securities, for example, a simple method is based on the least squared regression conditions, therefore determining the variance, standard deviation and co-variance between the two, finally deriving the correlation coefficient $\rho$ of them -if $\rho>0$, the two securities have positive relations ; $\rho<0$, the two are negatively correlated ; $\rho=0$, no relation between them . Then on this basis of the correlation, we can determine the proportion of each security. As for a investment combination which involves three or more variety of securities, in general we shall determine the relevant volatility of the portfolio first, then establishing the variance - co-variance matrix of all related securities, finally utilizing matrix inversion method to find the respective weight (value) of the securities . Once the price of relevant security changes, we need to make instantaneous adjustments to the matrix.

\subsection{Empirical Shows by Viewing 3 Securities}

Figure 1-1 shows variance-co-variance matrix for three kinds of securities - called A, B, C, and we already know: if we set the variance of returns of the Portfolio as $\sigma_{P}^{2}$, the respective weighted value of the securities as $W_{A}, W_{B}, W_{C}$, then $\rightarrow$

$$
\sigma_{P}^{2}=\sigma_{A}^{2} W_{A}^{2}+\sigma_{B}^{2} W_{B}^{2}+\sigma_{C}^{2} W_{C}^{2}+2 W_{A} W_{B} W_{C} \sum^{*} \operatorname{COV}(A, B, C)
$$

Where, $*=\frac{n^{2}-n}{2} ; \mathrm{n}$ is the numbers of securities $; \mathrm{COV}(\mathrm{A}, \mathrm{B}, \mathrm{C})$ is co-variance of Security $\mathrm{AB}, \mathrm{AC}$ and $\mathrm{BC}$. 
Figure 1-1. Matrix of Variance-co-variance of Security A, B, C

\begin{tabular}{|l|l|l|l|}
\hline & Security A & Security B & Security C \\
\hline Security A & $\sigma_{A}^{2}$ & $\operatorname{COV}(A, B)$ & $\operatorname{COV}(A, C)$ \\
\hline Security B & $\operatorname{COV}(A, B)$ & $\sigma_{B}^{2}$ & $\operatorname{COV}(B, C)$ \\
\hline Security C & $\operatorname{COV}(A, C)$ & $\operatorname{COV}(B, C)$ & $\sigma_{C}^{2}$ \\
\hline
\end{tabular}

On the basis of a given returns of Portfolio, we can define an acceptable relevant variance rate, then determining the respective weights of the securities. If we assume the returns rate of security as $r$, the relevant security price of Changing Period as $S_{T}$, price of Basic Period as $S_{t}$, then $r=\Delta \ln S=\ln S_{T}-\ln S_{t} \approx \frac{S_{T}-S_{t}}{S_{t}}$. However, $\mathrm{S}$ is a kind of random variable, thus leading to a changeable returns rate $(r)$. Accompanied with the upward or downward tendency of the vector $r$, the value of Variance - Co-variance Matrix will be changed — at that time , we should input "Transpose" order to relevant "Edit Procedure", then deriving the value of inverse matrix , finally rearranging the weights of relative securities .

The above-mentioned method is coming out of traditional portfolio theories by using the correlation among different securities to hedge risks and gain profits. As we know : co-variance of the two securities, for example $-\mathrm{A}$ and $\mathrm{B}$, is $\operatorname{COV}(A, B)$, where, $\operatorname{COV}(A, B)=\rho_{A B} \sigma_{A} \sigma_{B}$, if the correlation coefficient $\rho$ were to change against our expectation, could the matrix still works effectively? And how would we deal with this kind of problem ?

2. Correlation Problem arising from Traditional Theory

There are fickle fashion and essential greed in the capital flows, while, the purpose of establishing portfolio is to ensure the investors' capital gain with risk-free returns. But when the real correlation of various securities in a specified Portfolio is changing in the opposite direction to the Expected ones, investors will suffer from huge exposure to risk. The so called "instantaneous adjustment" cannot catch up with the moving financial market. Based on our experience, facing the reverse change of correlation against expectation, the proportion of losing investors is much than that of profiting investors. During the financial crisis in 2008, the international financial market evaporated 5 trillion U.S. Dollars - among them, the correlation problem of oil futures, paper gold tradings and USDYEN is the most serious. Despite the factors from malicious traders and funds, the majority of investors, especially Asian investors, need to recognize the theories related to portfolio from the technical level of thinking again!

\section{Thinking About Newly Covered Synthetic Securities}

Based on the theory of "Geometrical Brown Motion", the logarithmic form of the price of a security or Portfolio approximately adopts Standard Normal Distribution with specified "Drift Rate" and "Variance Rate", the mean is zero and the standard deviation is one. Now what we should do first is to bless all the securities in a portfolio into "one" security - setting the returns rate of portfolio as $r_{P}$, since $r_{P}=r_{A} W_{A}+r_{B} W_{B}+\ldots+r_{n} W_{n}$, we can determine the $r_{P}$ Curve very easily . Next let's assume "Drift Rate" and "Variance Rate" in normal financial market (real correlation among securities complying with the expected one) as $\mu_{1}$ and $\sigma_{1}^{2}$; setting $\mu_{2}$ and $\sigma_{2}^{2}$ for turbulent financial market (real correlation opposite to our expectation) ; the prices of "One Security" respectively as $S_{1}$ (in normal market) and $S_{2}$ (in turbulent market), then $\rightarrow$

$$
\begin{gathered}
d S_{1}=\mu_{1} S_{1} d t+\sigma_{1} S_{1} d z \\
d S_{2}=\mu_{2} S_{2} d t+\sigma_{2} S_{2} d z
\end{gathered}
$$

Where, $d z=\varepsilon \sqrt{d t}$

In the above equation, $\varepsilon$ is random variable, $\varepsilon " \sim \phi(0,1)$.

For the same value of $\varepsilon$ and the same metrics on Time Series, the discrete possibilities corresponding to $\mu$ and $\sigma$ in the two markets are different. As well, the respective type of dense function $f(x)$ is also different from 
each other. And as we know: $S=x$, and $f(x)=\frac{1}{\sqrt{2 \pi} \sigma} e^{-\frac{(x-\mu)^{2}}{2 \sigma^{2}}}$, so we can assume the type of dense function in normal financial market as Set A, and Set B for turbulent market. Then we should map Set A into standard normal distribution as Set $\mathrm{A}^{*}$, and Set B into Set $\mathrm{B}^{*}$, finally deriving the correlation coefficient between $\mathrm{A}^{*}$ and $\mathrm{B}^{*}$, this coefficient is called Copula $\rho$, according to it, we can determine the Value at Risk (VaR). Let's assume the possibility of turbulent market as $\mathrm{X}$, confidence level as $\mathrm{Q}$, time series as $\mathrm{T}$, then $\rightarrow$

$$
\operatorname{VaR}(T, X)=N\left\{\frac{N^{-1}[Q(T)]+\sqrt{\text { copula } \rho} N^{-1}(X)}{\sqrt{1-\text { copla } \rho}}\right\}
$$

In the course of using the above-mentioned method, we should bless all the securities in the Portfolio together, then dividing the normal or calm market and turbulent market into two equal Time Windows, then taking the factor of $\mathrm{VaR}$ into our consideration, finally respectively using derivative financial instrument called Option to hedge the relevant risks for every security position. For example, if the underlying assets is a kind of investment combination made up of Stocks and Index Futures, we first bless them together by dividing or multiplying method, thus determining a motion model of "One" security, after deriving VaR of the portfolio, we can respectively use Stock Option and Index Option to hedge relative risks accordingly.

Mr. Lovelady created Covered Synthetic Annuity (SynAs) in order to gain profits and returns with lower cost basis, by buying underlying assets, selling Call Option and buying Put Option. However, theoretically, the short position of Call Option will face unlimited losing risk, so as general investors, we'd better keep long position for either Call Option or Put Option. As well, the covered Option Contract Size must be contacted with the scale of VaR, therefore lowering relevant cost basis of the portfolio. Meanwhile, we should set "Stop Loss" points for every security in regarding Portfolio, once total loss goes beyond the scale of VaR of the portfolio, we should offset and leave financial market to be a "bystander".

Some financial experts think that: setting "stop loss" is a trading method, not an investing method. But the main idea of mine is to bless all securities in the portfolio together, as well as to bless trading methods and investing ones together. The main purpose of us is to earn risk-free returns with a lower cost basis, so some definitions need not to be clarified too clearly.

\section{Conclusion}

The purpose of Portfolio Theories is to form a combination involving different kinds of investments, therefore using correlation effects to hedge risks exposure to market from each other. However, if the relevant coefficient were to change adversely beyond our expectation, the investors might suffer a large scale of losses. So we must have new logic and ideas to solve such problem. First we should regard all the securities in a Portfolio as "One" instrument, then dividing the instrument into two equal time series, furthermore deriving the value of copula $\rho$, finding VaR proportion accordingly , using divergent Option contracts to hedge it , finally setting "stop loss" point for every security . What I want is to ensure a risk-free returns and profits for most of investors with a lower cost basis. I think: as the development of financial theories, the relative markets will house more and more investors and trades, collecting much more capital inside, thus making contributions to current Industries, Agriculture and Economies.

\section{References}

John C Hull. (2009). Risk Management and Financial Institutions. Peking China Machine Press, (9).

McCann, Craig \& Dengpan Luo. (2006). Are Structured Products Suitable for Retail Investors. Security Litigation and Consulting Group, Inc.

Michael Lovelady. (2013). Visual Quantitative Finance: A New Look at Option Pricing, Risk Management, and Structured Securities. Pearson Education, Inc. April 2013.

Paul

Wilmott

Blog. http://www.globalriskjobs.com/risk-careers/598926/Quantitative-Investment-Strategist-Tean-Lead-Region-Balti more?print

Zhen-Long Zheng. (2012). Financial Engineering. 3th edition. Beijing Higher Education Press, (6). 